\title{
Ceiling and Wall Illumination, Utilance, and Power in Interior Lighting
}

\author{
Piotr Pracki *(D), Michał Dziedzicki and Paulina Komorzycka
}

Lighting Technology Division, Electrical Power Engineering Institute, Warsaw University of Technology, 75 Koszykowa Street, 00-662 Warsaw, Poland; 00222342@pw.edu.pl (M.D.); 01027609@pw.edu.pl (P.K.)

* Correspondence: piotr.pracki@ien.pw.edu.pl

Received: 6 August 2020; Accepted: 3 September 2020; Published: 11 September 2020

\begin{abstract}
The common use of electric lighting in interiors has led to the need to search for user- and environmentally-friendly solutions. In this research, the impact of the luminaires and room parameters on the selected parameters of general lighting in interiors was assessed. To achieve the objective of this work, a computer simulation and statistical analysis of results were conducted. The illuminance uniformity on work plane, ceiling and wall relative illuminances, utilance, and normalized power density of lighting installations for 432 situations were analyzed in detail. The scenarios were varied in terms of room size, reflectance, lighting class, luminaire downward luminous intensity distribution, and layout. The lighting class was a factor having the highest impact on ceiling and wall illumination, utilance, and power. It was also shown that the impact of lighting class on ceiling illumination, utilance and power, was different in interiors of various sizes. The impact of reflectances and luminaire layouts on the analyzed parameters was significantly lower. The results also demonstrated that the use of different lighting classes gave the possibility of reducing the power of general lighting in interiors at a level of $30 \%$ on average. Based on the results, a classification of energy efficiency in general lighting in interiors was also proposed. Understanding the correlations between the lighting system used and the effects achieved is helpful in obtaining comfortable and efficient lighting solutions in interiors.
\end{abstract}

Keywords: lighting technology; smart building; interior lighting; luminous environment; energy efficiency

\section{Introduction}

Lighting is an essential topic in any debate on a building's environment. It is an important element of smart cities and buildings [1]. The significance of electric lighting arises from the wide range of its use and the large number of people's needs to be met [2].

The use of electric lighting in the modern world is common. With ongoing urbanization and societies growing wealthier and more active, the demand for lighting systems is increasing. The large scale use of artificial lighting forces us to search for the solutions that are energy-efficient [3-5], environmentally friendly [6,7], and economically rational $[8,9]$. These three aspects are very important while evaluating any lighting solution. However, they cannot obscure the pursuit of the fundamental lighting function which is the need to create a luminous environment enabling people to work and stay in private and public spaces efficiently, comfortably and, as a consequence, safely [10,11].

Creating a good luminous environment has an impact on the human body and psyche. Lighting determines the efficiency of visual activities [12,13] and regulates circadian-featured life processes [14,15]. It can also affect the perception of lit spaces and objects [16,17], and determine feelings, emotions, moods, and behavior $[18,19]$. It is also associated with the aesthetic reception of illuminated places $[20,21]$. 
Investigating lighting quality is a fundamental scientific topic in contemporary illuminating engineering [22-24], including the issues of smart cities and buildings [25]. Studying relationships between the quality of luminous environment and energy efficiency of lighting solution in interiors has been an important research issue for a long time and is demonstrated in this paper.

The luminous environment and energy efficiency of lighting solutions in interiors are subject to assessment. The basic evaluation criteria include, as follows [26,27]:

- The level of illuminance and uniformity on the work plane;

- The level of illuminance and uniformity on the ceiling,

- The level of illuminance and uniformity on walls;

- The level of cylindrical illuminance and uniformity on the reference plane;

- The distribution of modeling index on the reference plane;

- The level of glare and luminaire luminance;

- The light color and fidelity of color rendering;

- The level of power and energy consumption of lighting.

Illuminance distribution on work planes, ceiling, and walls, in conjunction with the reflectances of these planes, significantly affects luminance distribution in interiors. The luminance distribution determines a degree of visual adaptation, performance, and comfort. The interior perception and general satisfaction associated with staying in the illuminated spaces is connected with the luminance distribution. Considering the possibilities of creating the different illuminance distributions that affect the luminance distribution in interiors is an interesting research issue.

The practical evaluation of the work plane, ceiling, and wall illumination in interiors consists of checking compliance with normative criteria. These requirements in the European Union countries are specified in the standard [26]. As for illuminating the work plane, they apply to checking the average illuminance and uniformity levels. These requirements are specified, among others, depending on a type of the room and visual activities performed. In terms of the ceiling and wall illumination, the requirements also apply to checking the average illuminance and uniformity levels, as well as the reflectances of the ceiling, walls, floor, and large objects in the interior.

The practical assessment of lighting energy efficiency involves checking its compliance with normative requirements either. These criteria in the EU countries are specified in the standard [27]. Formally, the requirements apply to the assessment of entire buildings based on lighting power or energy density. Development of LED technology and a significant improvement in the luminous efficacy of LED light sources force us to verify power and energy density levels to evaluate the energy efficiency of lighting solutions.

Searching for the most satisfactory lighting solution in a room is a challenging task [28,29]. Apart from the demand for meeting a large number of requirements, it also arises from a multitude of other factors that should be taken into account in this process. These factors apply to rooms, lighting systems, and ways to use them for illumination. The difficulty in searching for a good solution also results from a multitude of connections between the lighting systems used and the effects achieved.

One of the scientific topics undertaken in this area is an attempt to determine a degree of impact of the parameters characterizing rooms, luminaires, and their layouts on the parameters characterizing the luminous environment and energy efficiency of interior lighting. The research in this area is carried out by Makaremi et al. and the results are presented in two publications [30,31].

In their first paper [30], the impact of interior reflectances on the levels of three photometric parameters, average illuminance and uniformity on the work plane and discomfort glare index, was assessed. In a small room illuminated with one luminaire centrally located on the ceiling, the photometric parameters for 64 lighting scenarios were calculated. The situations were varied in ceiling, wall, and floor reflectances. It was found that the wall reflectance had the highest impact, and the floor reflectance had a negligible effect on the analyzed photometric parameters. 
In their second paper [31], the impact of interior reflectances, luminaire type, number of luminaires, and luminaire suspension height on the levels of the same three photometric parameters and lighting power was assessed. In the same small room, the analyzed parameters were calculated for 135 lighting scenarios. They were differentiated by the interior reflectances, luminaire type, and the number and suspension height of the luminaires. It was found that the luminaire type had a decisive impact on the analyzed photometric parameters. The significant impact of reflectances on the photometric parameters was confirmed and their effect on the lighting power was also noticed. It was estimated that as a result of using high reflectance in the interior, a reduction of $45 \%$ in electricity consumption could be expected. The need to integrate various lighting strategies in the quest of providing low energy demand and high lighting quality in interiors was also recognized.

The gained results have high cognitive values, however, they refer to the narrowed cases, including the room size. It is also worth paying attention to the supposition presented in the conclusions that in the larger rooms, "the influence of different lighting strategies and surface properties on energy consumption and visual comfort might be significantly higher" [31].

Bearing in mind the importance and complexity of this issue, it is purposeful to conduct research in this area and to take into account the impact of other parameters characterizing the room and the way of illumination, as well as other lighting parameters in interiors. That is why this task was undertaken and the results gained are presented in this paper.

The main objectives of this research were as follows:

- To determine the levels of uniformity on the work plane, ceiling and wall relative illuminances, lighting installation utilance, and normalized power density for general lighting in interiors;

- To evaluate the impact of room characteristics, luminaires, and their layouts on the uniformity of the work plane, ceiling and wall relative illuminances, lighting installation utilance, and normalized power density for general lighting in interiors;

- To present the proposal for the energy efficiency classification for general lighting in interiors.

The original contributions of this research were as follows:

- To extend the scope of research in the undertaken topic in terms of room sizes, lighting classes, luminous intensity distributions, and layouts of general lighting luminaires;

- To extend the scope of research in the undertaken topic in terms of the interior lighting parameters-uniformity on work plane, ceiling and wall relative illuminances, lighting installation utilance, and normalized power density—-for general lighting in interiors,

- To propose a classification, for the assessment of the energy efficiency of interior lighting, based on the normalized power density.

\section{Methods}

To achieve the objective of this work, the results of the computer simulations and their statistical analysis were used. The calculations of the parameters characterizing the quality of luminous environment in interiors were made using the DIALux 4.13 software. It is a tool verified [32] and used in research on interior lighting [30,31,33,34]. The Statistica package [35] was applied to calculate the lighting power and to analyze the results. Before starting the computer simulation, it was necessary to make some assumptions about the rooms, luminaires, their layouts, and calculations.

\subsection{Luminaires}

For this research, 16 types of luminaires with different theoretical and rotationally symmetrical luminous intensity distributions were selected. The luminaires representing 4 lighting classes and 4 widths of luminaire downward luminous intensity distribution were investigated. The CIE (International Commission on Illumination) luminous flux indices [36] were selected to describe the luminaire lighting class and width of downward luminous intensity distribution. 
The use of different lighting classes is associated with the distribution of luminous flux of luminaires in the range of lower and upper hemisphere. The CIE luminous flux index N4 of a luminaire was accepted as the parameter describing the lighting class. The lighting classes were labeled with Roman numerals (I—direct lighting: N4 = 1.00, II—semi direct lighting: N4 $=0.75$, III—direct-indirect lighting: N4 $=0.50$, IV—semi indirect lighting: N4 $=0.25$ ).

Four widths of luminaire downward luminous intensity distribution were considered for each lighting class. The CIE luminous flux index N1 of a luminaire was accepted as the parameter describing the distribution width. The luminaire downward luminous intensity distributions were labeled with Arabic numerals ( 1 -the widest distribution: $\mathrm{N} 1=0.44,2$-the relatively wide distribution: $\mathrm{N} 1=0.58$, 3 -the relatively narrow distribution: $\mathrm{N} 1=0.69,4$-the narrowest distribution: $\mathrm{N} 1=0.77$ ).

The luminous flux value of luminaires was individually adjusted in each lighting situation. The luminous efficacy (LE) of luminaires equal to $100 \mathrm{~lm} / \mathrm{W}$ and light output ratio (LOR) of luminaires equal to 0.80 were also assumed to calculate the lighting power. The luminous intensity distributions, markings, and percentage values of the CIE luminous flux indices of the luminaires for the research are presented in Figure 1.

\subsection{Rooms and Luminaire Layouts}

In order to investigate the impact of room characteristics and luminaire layouts on the photometric parameters and lighting power, it was necessary to make some assumptions regarding the room size, reflectances, and luminaire layouts. The following assumptions were made:

- The empty rooms with a square base (floor) were considered;

- The height of work plane was assumed at the height of $0.75 \mathrm{~m}$ above the floor;

- The luminaires of class i were located on the ceiling, and the ones of class ii, iii, and iv were suspended by $0.5 \mathrm{~m}$ from the ceiling;

- The spacing (s) between the centers of the adjacent luminaires in the lines was twice as large as the spacing between the centers of the outermost luminaires from the nearest wall;

- The lengths of rooms (l) and the number of luminaires (n) resulted from the accepted room indices (ri), the height of suspension of the luminaires above the work plane (h), and the spacing between the centers of the adjacent luminaires related to the suspension height above the work plane (SH).

There were 27 situations analyzed resulting from the combination of:

- $\quad$ RI indices: $\mathrm{RI}=1.5$ (relatively small rooms), $\mathrm{RI}=3.0$ (rooms of moderate size), $\mathrm{RI}=4.5$ (relatively large rooms);

- $\quad \mathrm{SH}$ indices: $\mathrm{SH}=1.5$ (large spacing relative to suspension height), $\mathrm{SH}=1.0$ (moderate spacing relative to suspension height), $\mathrm{SH}=0.5$ (small spacing relative to suspension height);

- RE reflectances: RE: 752 ( 0.7 for the ceiling, 0.5 for the walls, 0.2 for the floor), RE: 753 ( 0.7 for the ceiling, 0.5 for the walls, 0.3 for the floor) and RE: 772 ( 0.7 for the ceiling, 0.7 for the walls, 0.2 for the floor).

The list of parameters characterizing the rooms and luminaire layouts are presented in Table 1 and Figure 2. There were 432 lighting situations analyzed in total. 


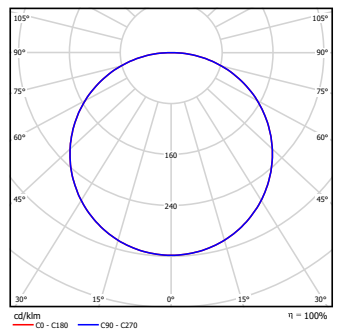

Luminaire I1

Code flux: 44759410080

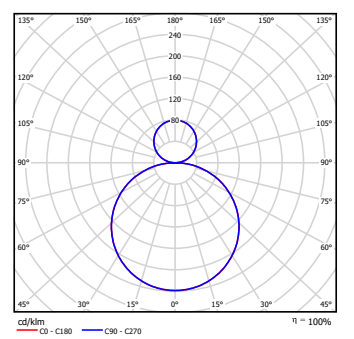

Luminaire II1

Code flux: 4475947580

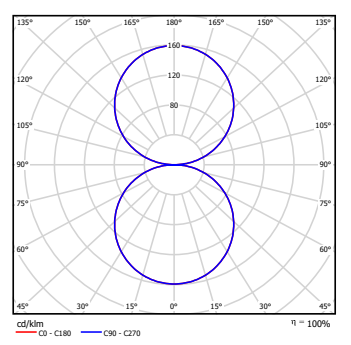

Luminaire III1

Code flux: 4475945080

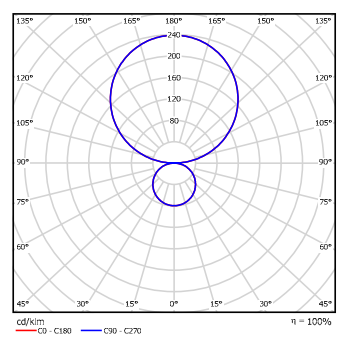

Luminaire IV1

Code flux: 4475942580

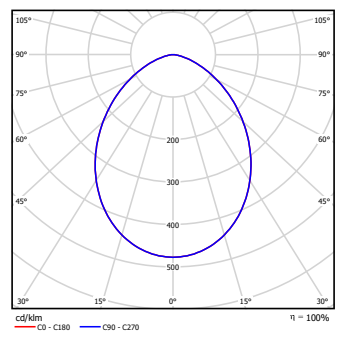

Luminaire I2

Code flux: 58889810080

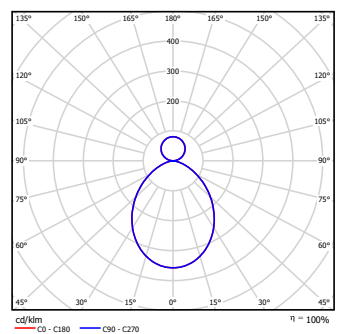

Luminaire II2

Code flux: 5888987580

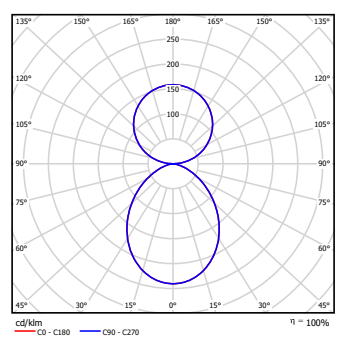

Luminaire III2

Code flux: 5888985080

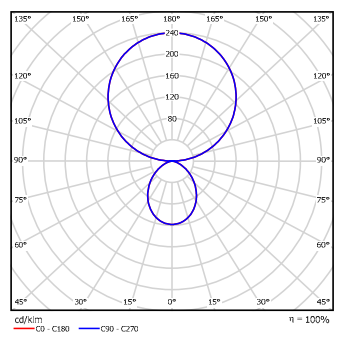

Luminaire IV2

Code flux: 5888982580

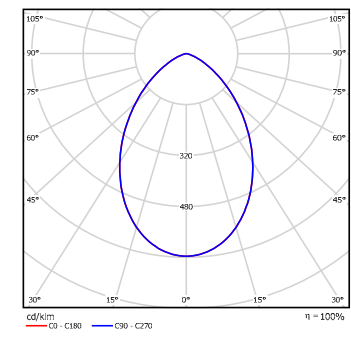

Luminaire I3

Code flux: 699410010080

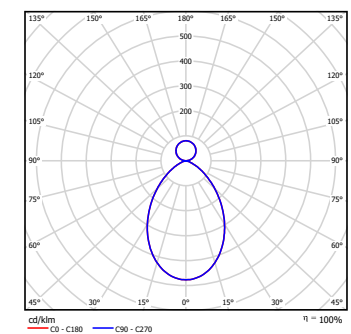

Luminaire II3

Code flux: 69941007580

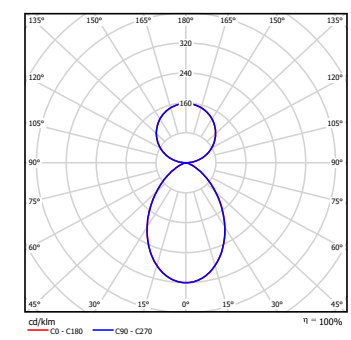

Luminaire III3

Code flux: 69941005080

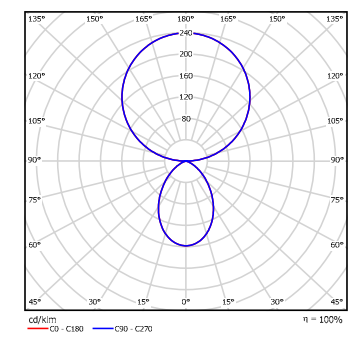

Luminaire IV3

Code flux: 69941002580

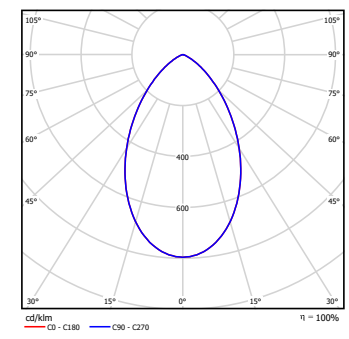

Luminaire I4

Code flux: 779710010080

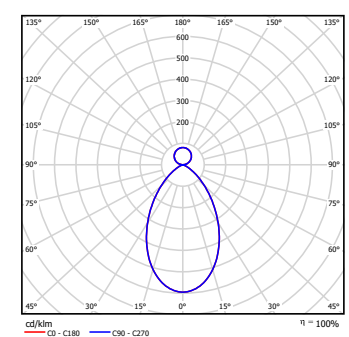

Luminaire II4

Code flux: 77971007580

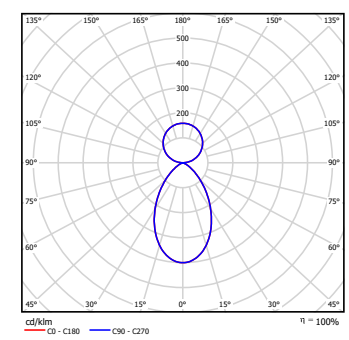

Luminaire III4

Code flux: 77971005080

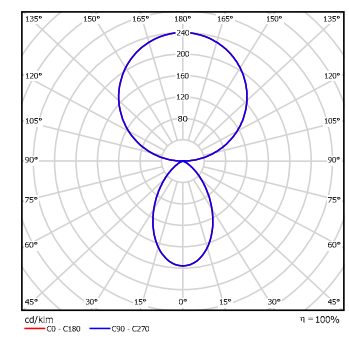

Luminaire IV4

Code flux: 77971002580

Figure 1. Characteristics of the luminaires for the study. 
Table 1. The rooms and luminaire layouts parameters for the study.

\begin{tabular}{ccccc}
\hline RI & SH & H & N & L \\
\hline \multirow{3}{*}{1.5} & 0.5 & 3 & $36(6 \times 6)$ & 9 \\
& 1 & 2 & $9(3 \times 3)$ & 6 \\
& 1.5 & 2 & $4(2 \times 2)$ & 6 \\
\hline \multirow{3}{*}{3} & 0.5 & 3 & $144(12 \times 12)$ & 18 \\
& 1 & 2 & $36(6 \times 6)$ & 12 \\
& 1.5 & 2 & $16(4 \times 4)$ & 12 \\
\hline \multirow{3}{*}{4.5} & 0.5 & 3 & $324(18 \times 18)$ & 27 \\
& 1 & 2 & $81(9 \times 9)$ & 18 \\
& 1.5 & 2 & $36(6 \times 6)$ & 18 \\
\hline
\end{tabular}

RI [37] is the number representative of the geometry of the part of the room between the work plane and the plane of the luminaires. For the rooms of the same floor area $(L=18 \mathrm{~m})$ : $\mathrm{RI}=3.0$ for $\mathrm{H}=3 \mathrm{~m}$ and $\mathrm{RI}=4.5$ for $\mathrm{H}=2 \mathrm{~m}$.
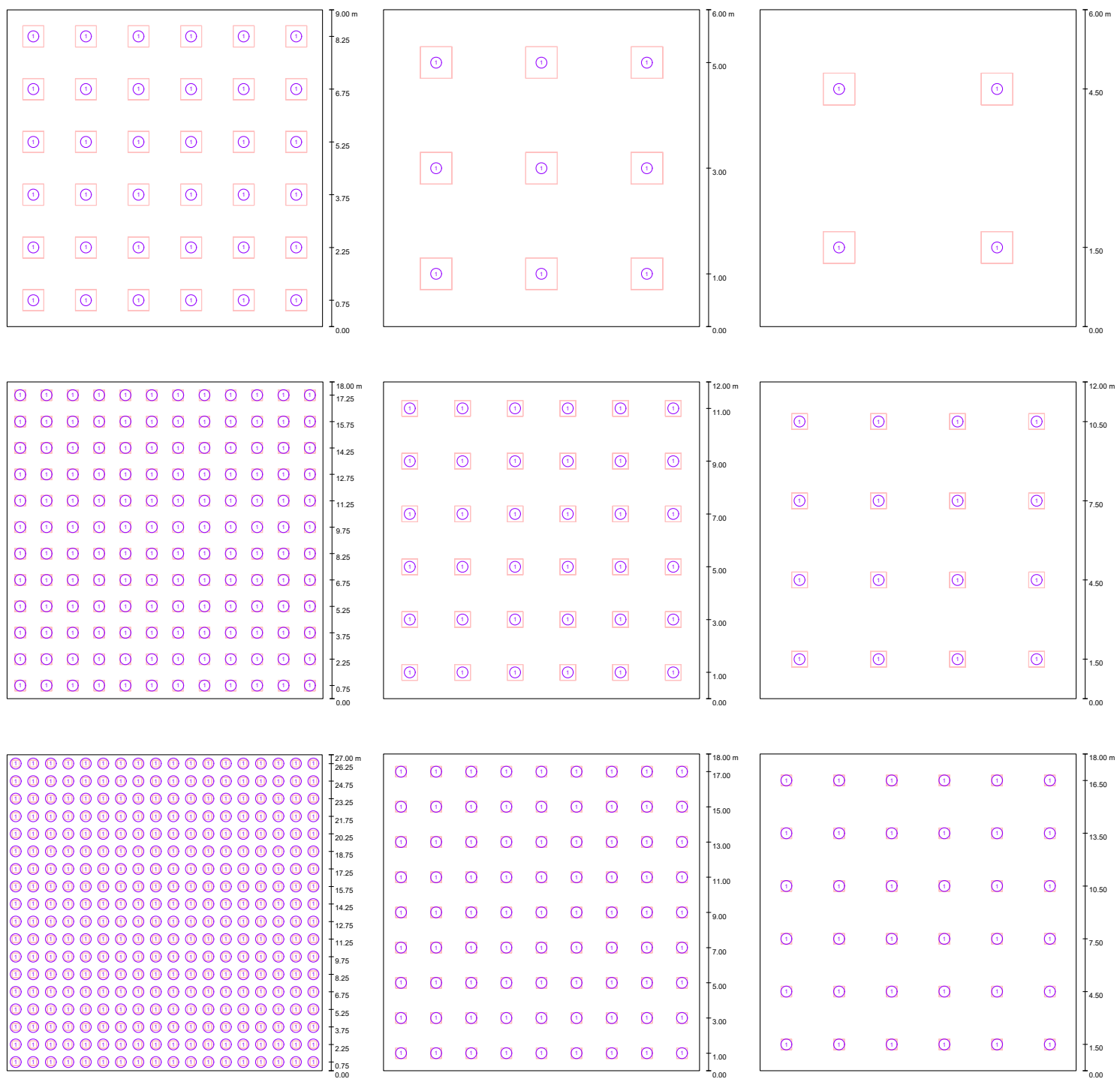

Figure 2. The luminaire layouts for the study. Top row, left: $\mathrm{RI}=1.5, \mathrm{SH}=0.5$; Top row, middle: $\mathrm{RI}=1.5$, $\mathrm{SH}=1$; Top row, right: $\mathrm{RI}=1.5, \mathrm{SH}=1.5$; Middle row, left: $\mathrm{RI}=3, \mathrm{SH}=0.5$; Middle row, middle: $\mathrm{RI}=3$, $\mathrm{SH}=1$; Middle row, right: $\mathrm{RI}=3, \mathrm{SH}=1.5$; Bottom row, left: $\mathrm{RI}=4.5, \mathrm{SH}=0.5$; Bottom row, middle: $\mathrm{RI}=4.5, \mathrm{SH}=1$; Bottom row, right: $\mathrm{RI}=4.5, \mathrm{SH}=1.5$. 


\subsection{Calculations}

In the study, the following parameters characterizing the luminous environment and energy efficiency of the interior lighting were examined in detail:

- The illuminance uniformity on work plane: UN [-];

- The ceiling relative illuminance: EC/EN [-];

- The wall relative illuminance: EW/EN [-];

- The lighting installation utilance: UT [-];

- The lighting installation normalized power density: PN [W/m² per $100 \mathrm{~lx}]$.

The illuminance distribution on work plane was calculated by adjusting the luminaire luminous flux (FLU) in each situation individually in order to obtain the average maintained illuminance on the work plane (EN) exactly equal to $500 \mathrm{~lx}$. The uniformities on the work plane (UN) were calculated based on the illuminance distributions on the work plane. Based on the results of illuminance distributions on ceiling, first the average maintained ceiling illuminances (EC) were calculated and then the ceiling ratios (EC/EN). Based on the results of illuminance distributions on walls, first the average maintained wall illuminances (EW) were calculated, and then the wall ratios (EW/EN). To calculate the illuminance distributions, the grid density was accepted in accordance with the recommendations [26]. The calculations were made for the luminous efficacy (LE) of luminaires equal to $100 \mathrm{~lm} / \mathrm{W}$, light output ratio (LOR) of luminaires equal to 0.80 , and maintenance factor (MF) equal to 0.8 .

The lighting installation utilance (UT) was calculated using the following equation:

$$
\mathrm{UT}=\frac{\mathrm{EN} \cdot \mathrm{L}^{2}}{\mathrm{~N} \cdot \mathrm{FLU} \cdot \mathrm{MF}}
$$

The lighting installation normalized power density $(\mathrm{PN})$ was calculated using the equation:

$$
\mathrm{PN}=\frac{100}{\mathrm{LE} \cdot \mathrm{UT} \cdot \mathrm{LOR} \cdot \mathrm{MF}}
$$

\section{Results and Discussion}

\subsection{General Results}

At the first stage of the research, the basic calculation results of the analyzed parameters were set for all the cases in total. Table 2 presents the list of the mean (Mean), minimum (Min), maximum (Max), range (R), and standard deviations of mean (SD). The histograms are presented in Figure 3 for UN, in Figure 4 for EC/EN and EW/EN, and in Figure 5 for UT and PN100. PN100 indicates lighting installation normalized power density with $\mathrm{LE}=100 \mathrm{~lm} / \mathrm{W}, \mathrm{LOR}=0.80$, and $\mathrm{MF}=0.8$.

Table 2. The mean, minimum, maximum, range, and standard deviation values for illuminance uniformity UN, EC/EN, EW/EN, UT, and PN100.

\begin{tabular}{lcccccc}
\hline Parameter & Cases & Mean & Min & Max & R & SD \\
\hline UN & 432 & 0.663056 & 0.470000 & 0.830000 & 0.360000 & 0.061281 \\
EC/EN & 432 & 0.730093 & 0.154000 & 1.652000 & 1.498000 & 0.414923 \\
EW/EN & 432 & 0.510241 & 0.296000 & 0.708000 & 0.412000 & 0.092393 \\
UT & 432 & 0.843307 & 0.525762 & 1.157407 & 0.631645 & 0.143200 \\
PN100 & 432 & 1.910616 & 1.350000 & 2.971875 & 1.621875 & 0.348665 \\
\hline
\end{tabular}




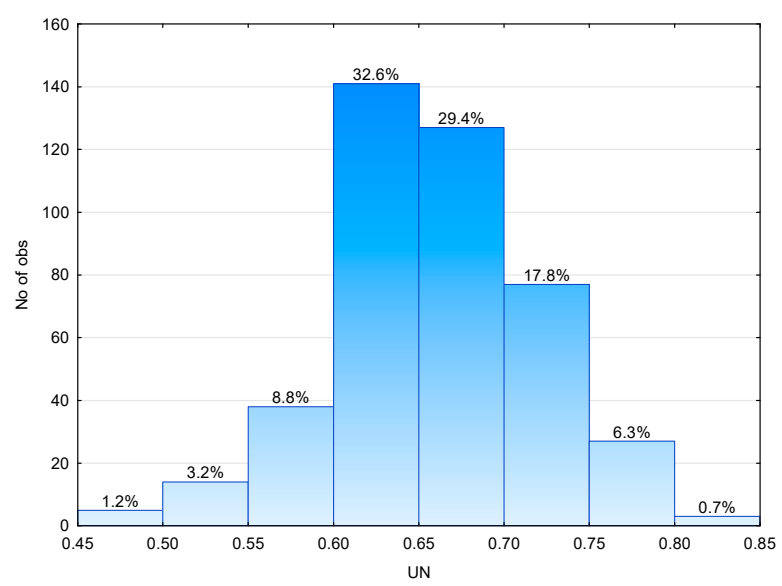

Figure 3. Histogram of uniformity UN for the analyzed cases.
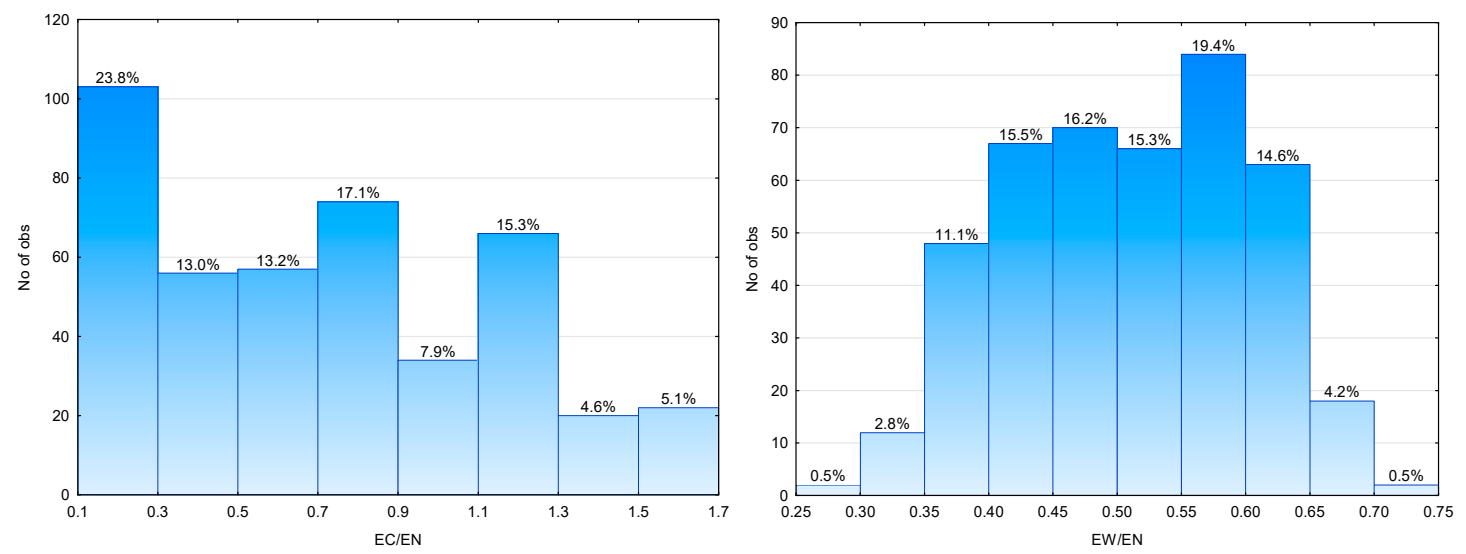

Figure 4. Histograms of EC/EN and EW/EN for the analyzed cases.
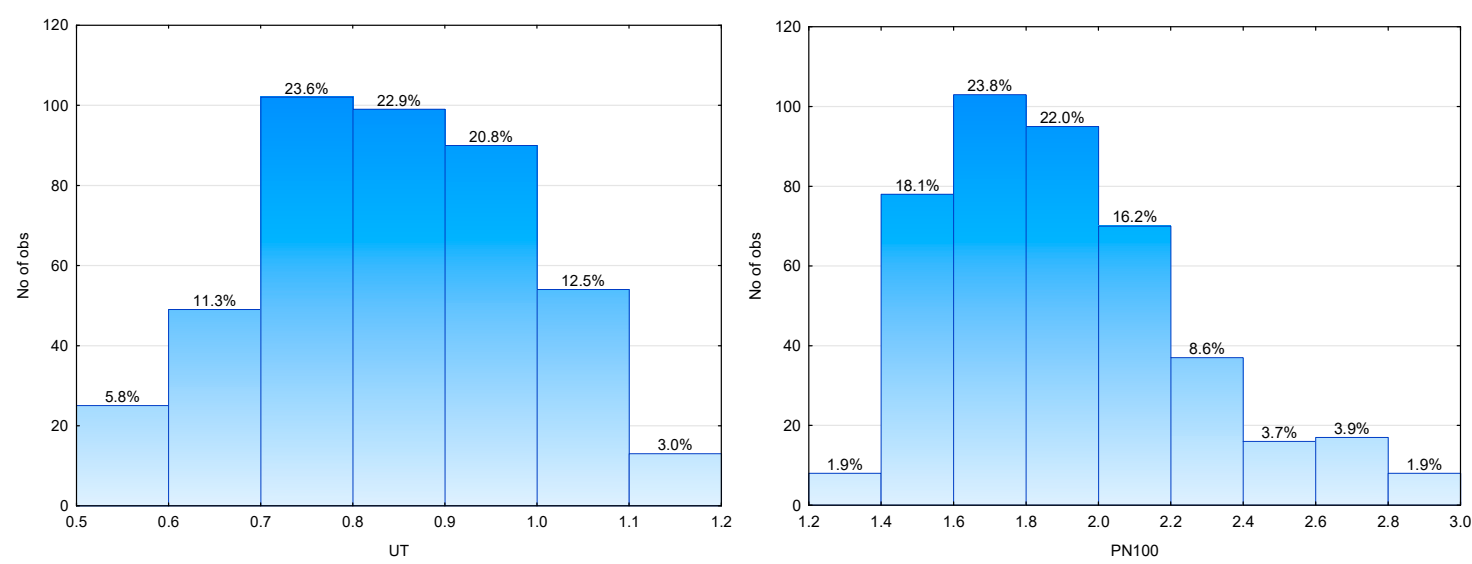

Figure 5. Histograms of UT and PN100 for the analyzed cases.

It is worth noting that the illuminance uniformity (UN) was below the level of 0.6 for only about $13 \%$ of cases, the ceiling ratio (EC/EN) was below the level of 0.3 for about $24 \%$ of the cases, and the wall ratio (EW/EN) was below the level of 0.5 as for about $46 \%$ of the cases. The utilance (UT) was always higher than the level of 0.5 , and for $15.5 \%$ of the cases, it was higher than 1.0. In contrast, the normalized power density (PN100) was below the level of $3 \mathrm{~W} / \mathrm{m}^{2}$ per $100 \mathrm{~lx}$ in any case, and for about $65 \%$ of cases, it was even below the level of $2 \mathrm{~W} / \mathrm{m}^{2}$ per $100 \mathrm{~lx}$.

The analyzed solutions for general lighting in interiors enabled us to widely create the luminous flux distribution and illuminances, as well as to achieve the low normalized power density levels. 


\subsection{Impact of Room and Luminaire Parameters}

At the next stage of this research, the impact of the room and luminaire parameters on the analyzed parameters was considered. The degree of impact was assessed on the basis of changes in the mean values of each of the analyzed parameters.

\subsubsection{Impact of Room Size (RI)}

To determine the impact of room size, the calculation results were divided into three groups corresponding to the levels of the analyzed RI indices. Table 3 presents the mean (Mean), minimum (Min), maximum (Max), range (R), and standard deviations of the mean (SD) values for the analyzed parameters. The uniformity (UN) increased with the growth in RI level. When comparing the solutions for $\mathrm{RI}=1.5$ and $\mathrm{RI}=3.0$, this growth was $5.1 \%$, whereas while comparing the solutions for $\mathrm{RI}=3.0$ and $\mathrm{RI}=4.5$, the increase was $8.3 \%$. When comparing the edge solutions $(\mathrm{RI}=1.5$ and $\mathrm{RI}=4.5)$, the growth was $14 \%$. The EC/EN ceiling ratio increased with the fall in RI level. When comparing the solutions for $\mathrm{RI}=4.5$ and $\mathrm{RI}=3.0$, this growth was $6.2 \%$, however, while comparing the solutions for $\mathrm{RI}=3.0$ and $\mathrm{RI}=1.5$, the increase was $17 \%$. When comparing the edge solutions $(\mathrm{RI}=4.5$ and $\mathrm{RI}=1.5)$, the growth was $24 \%$. The EW/EN wall ratio also increased with the fall in RI level. Nevertheless, this growth was small and while comparing the edge solutions ( $\mathrm{RI}=4.5$ and $\mathrm{RI}=1.5$ ), it was $6.3 \%$. The utilance (UT) went up with the growth in RI level. When comparing the solutions for RI $=1.5$ and $\mathrm{RI}=3.0$, this increase was $18 \%$, whereas while comparing the solutions for $\mathrm{RI}=3.0$ and $\mathrm{RI}=4.5$, the growth was $6.8 \%$. When comparing the edge solutions ( $\mathrm{RI}=1.5$ and $\mathrm{RI}=4.5$ ), the increase was $26 \%$. The normalized power density (PN100) fell with the growth in RI level. When comparing the solutions for $\mathrm{RI}=1.5$ and $\mathrm{RI}=3.0$, this decrease was $16 \%$, whereas while comparing the solutions for $\mathrm{RI}=3.0$ and $\mathrm{RI}=4.5$, the fall was $6.4 \%$. When comparing the edge solutions ( $\mathrm{RI}=1.5$ and $\mathrm{RI}=4.5$ ), the decrease was $21 \%$. The changes in RI had a significant impact on changes in UT, EC/EN, PN100 and UN.

Table 3. Variation of lighting parameters for each room index (RI).

\begin{tabular}{lccccccc}
\hline Parameter & RI & Cases & Mean & Min & Max & R & SD \\
\hline UN & & 144 & 0.623681 & 0.470000 & 0.720000 & 0.250000 & 0.054230 \\
EC/EN & & 144 & 0.822347 & 0.154000 & 1.652000 & 1.498000 & 0.483654 \\
EW/EN & 1.5 & 144 & 0.529278 & 0.296000 & 0.708000 & 0.412000 & 0.099866 \\
UT & & 144 & 0.733723 & 0.525762 & 1.032110 & 0.506348 & 0.124289 \\
PN100 & & 144 & 2.190647 & 1.513889 & 2.971875 & 1.457986 & 0.368652 \\
\hline UN & & 144 & 0.655625 & 0.530000 & 0.760000 & 0.230000 & 0.046012 \\
EC/EN & & 144 & 0.704569 & 0.176000 & 1.342000 & 1.166000 & 0.383177 \\
EW/EN & 3.0 & 144 & 0.503750 & 0.304000 & 0.662000 & 0.358000 & 0.087798 \\
UT & & 144 & 0.868640 & 0.674460 & 1.088008 & 0.413547 & 0.114277 \\
PN100 & & 144 & 1.830218 & 1.436111 & 2.316667 & 0.880556 & 0.242401 \\
\hline UN & & 144 & 0.709861 & 0.600000 & 0.830000 & 0.230000 & 0.049374 \\
EC/EN & & 144 & 0.663361 & 0.178000 & 1.248000 & 1.070000 & 0.352752 \\
EW/EN & 4.5 & 144 & 0.497694 & 0.300000 & 0.656000 & 0.356000 & 0.086495 \\
UT & & 144 & 0.927558 & 0.735294 & 1.157407 & 0.422113 & 0.115809 \\
PN100 & & 144 & 1.710983 & 1.350000 & 2.125000 & 0.775000 & 0.214785 \\
\hline & & & & & &
\end{tabular}

\subsubsection{Impact of Reflectances (RE)}

In order to determine the impact of reflectances, the calculation results were divided into three groups corresponding to the levels of the analyzed reflectance sets (RE). Table 4 presents the mean (Mean), minimum (Min), maximum (Max), range (R), and standard deviations of the mean (SD) values for the analyzed parameters. 
Table 4. Variation of lighting parameters for each set of reflectances (RE).

\begin{tabular}{lccccccc}
\hline Parameter & RE & Cases & Mean & Min & Max & R & SD \\
\hline UN & & 144 & 0.645139 & 0.470000 & 0.800000 & 0.330000 & 0.055344 \\
EC/EN & & 144 & 0.714611 & 0.154000 & 1.648000 & 1.494000 & 0.433780 \\
EW/EN & 752 & 144 & 0.489222 & 0.296000 & 0.680000 & 0.384000 & 0.093326 \\
UT & & 144 & 0.808932 & 0.525762 & 1.088008 & 0.562245 & 0.140508 \\
PN100 & & 144 & 1.994100 & 1.436111 & 2.971875 & 1.535764 & 0.370243 \\
\hline UN & & 144 & 0.643819 & 0.470000 & 0.780000 & 0.310000 & 0.052210 \\
EC/EN & & 144 & 0.757819 & 0.210000 & 1.652000 & 1.442000 & 0.413174 \\
EW/EN & 753 & 144 & 0.527347 & 0.338000 & 0.708000 & 0.370000 & 0.088419 \\
UT & & 144 & 0.850002 & 0.541126 & 1.157407 & 0.616282 & 0.153930 \\
PN100 & & 144 & 1.903354 & 1.350000 & 2.887500 & 1.537500 & 0.370531 \\
\hline UN & & 144 & 0.700208 & 0.500000 & 0.830000 & 0.330000 & 0.058686 \\
EC/EN & & 144 & 0.717847 & 0.196000 & 1.536000 & 1.340000 & 0.398555 \\
EW/EN & 772 & 144 & 0.514153 & 0.318000 & 0.698000 & 0.380000 & 0.091905 \\
UT & & 144 & 0.870987 & 0.618132 & 1.118290 & 0.500158 & 0.127914 \\
PN100 & & 144 & 1.834394 & 1.397222 & 2.527778 & 1.130556 & 0.281258 \\
\hline
\end{tabular}

The uniformity (UN) did not practically change with increasing the floor reflectance and increased by $8.5 \%$ with raising the wall reflectance. The EC/EN ceiling ratio went up by $6.0 \%$ with raising the floor reflectance and did not practically change when increasing the wall reflectance. The EW/EN wall ratio went up by $7.8 \%$ with raising the floor reflectance and increased by $5.1 \%$ with raising the wall reflectance. The utilance (UT) increased by $5.1 \%$ with growing the floor reflectance and went up by $7.7 \%$ with the increase in wall reflectance. The normalized power density (PN100) fell by $4.8 \%$ with the increase in floor reflectance and went down by $7.1 \%$ with the growth in the wall reflectance. All changes in average values due to the increase in floor or wall reflectance were negligible (lower than $10 \%)$.

\subsubsection{Impact of Lighting Class (N4)}

In order to determine the impact of the lighting class, the calculation results were divided into four groups corresponding to the levels of the analyzed N4 indices. Table 5 presents the mean (Mean), minimum (Min), maximum (Max), range (R), and standard deviations of the mean (SD) values for the analyzed parameters.

The illuminance uniformity (UN) went up with the fall in N4 level. However, this increase was low and amounted to $4.5 \%$ when comparing the edge solutions for $\mathrm{N} 4=1.00$ and $\mathrm{N} 4=0.25$. The EC/EN ceiling ratio also grew with the fall in N4 level. When comparing the solutions for N4 $=1.00$ and $\mathrm{N} 4=0.75$, this increase was $116 \%$, and while comparing the solutions for $\mathrm{N} 4=0.50$ and $\mathrm{N} 4=0.25$, this increase was $53 \%$. When comparing the edge solutions $(\mathrm{N} 4=1.00$ and $\mathrm{N} 4=0.25)$, this growth exceeded $450 \%$. The EW/EN wall ratio also went up with the decrease in N4 level. However, when comparing the solutions for $\mathrm{N} 4=1.00$ and $\mathrm{N} 4=0.75$, the changes were negligible, and when comparing the solutions for $\mathrm{N} 4=0.50$ and $\mathrm{N} 4=0.25$, the growth in EW/EN was $13 \%$. When comparing the edge solutions ( $\mathrm{N} 4=1.00$ and N4 $=0.25$ ), this growth was $24 \%$. The utilance (UT) went up with the increase in N4 level. While comparing the solutions for $\mathrm{N} 4=0.25$ and $\mathrm{N} 4=0.50$, this increase amounted to $14 \%$, whereas when comparing the solutions for $\mathrm{N} 4=0.75$ and $\mathrm{N} 4=1.00$, this increase was $12 \%$. When comparing the edge solutions ( $\mathrm{N} 4=0.25$ and $\mathrm{N} 4=1.00)$, the growth was $42 \%$. The normalized power density (PN100) went down with the growth in N4 level. When comparing the solutions for $\mathrm{N} 4=0.25$ and $\mathrm{N} 4=0.50$, this fall was $12 \%$, whereas while comparing the solutions for $\mathrm{N} 4=0.75$ and $\mathrm{N} 4=1.00$, the fall was $11 \%$. When comparing the edge solutions ( $\mathrm{N} 4=0.25$ and $\mathrm{N} 4=1.00$ ), the decrease was $30 \%$. The changes in N4 level had the highest impact on the change in $\mathrm{EC} / \mathrm{EN}$. They also significantly affected the changes in UT, PN and EW/EN. 
Table 5. Variation of lighting parameters for each lighting class (N4 index).

\begin{tabular}{lccccccc}
\hline Parameter & N4 & Cases & Mean & Min & Max & R & SD \\
\hline UN & & 108 & 0.680926 & 0.570000 & 0.790000 & 0.220000 & 0.047920 \\
EC/EN & & 108 & 1.314148 & 1.102000 & 1.652000 & 0.550000 & 0.160683 \\
EW/EN & 0.25 & 108 & 0.584278 & 0.494000 & 0.706000 & 0.212000 & 0.045333 \\
UT & & 108 & 0.698214 & 0.525762 & 0.810519 & 0.284756 & 0.085593 \\
PN100 & & 108 & 2.274569 & 1.927778 & 2.971875 & 1.044097 & 0.303921 \\
\hline UN & & 108 & 0.665000 & 0.510000 & 0.810000 & 0.300000 & 0.059476 \\
EC/EN & & 108 & 0.858056 & 0.722000 & 1.096000 & 0.374000 & 0.092157 \\
EW/EN & 0.50 & 108 & 0.517204 & 0.402000 & 0.676000 & 0.274000 & 0.065837 \\
UT & & 108 & 0.794741 & 0.589623 & 0.923645 & 0.334023 & 0.090088 \\
PN100 & & 108 & 1.993673 & 1.691667 & 2.650000 & 0.958333 & 0.247536 \\
\hline UN & & 108 & 0.654907 & 0.480000 & 0.820000 & 0.340000 & 0.064540 \\
EC/EN & & 108 & 0.511500 & 0.426000 & 0.650000 & 0.224000 & 0.052185 \\
EW/EN & 0.75 & 108 & 0.466704 & 0.320000 & 0.654000 & 0.334000 & 0.082750 \\
UT & & 108 & 0.887030 & 0.652742 & 1.028336 & 0.375595 & 0.094918 \\
PN100 & & 108 & 1.783706 & 1.519444 & 2.393750 & 0.874306 & 0.211013 \\
\hline UN & & 108 & 0.651389 & 0.470000 & 0.830000 & 0.360000 & 0.067802 \\
EC/EN & & 108 & 0.236667 & 0.154000 & 0.344000 & 0.190000 & 0.040313 \\
EW/EN & 1.00 & 108 & 0.472778 & 0.296000 & 0.708000 & 0.412000 & 0.110621 \\
UT & & 108 & 0.993242 & 0.730519 & 1.157407 & 0.426888 & 0.099493 \\
PN100 & & 108 & 1.590516 & 1.350000 & 2.138889 & 0.788889 & 0.176540 \\
\hline
\end{tabular}

3.2.4. Impact of Downward Luminous Intensity Distribution (N1)

In order to determine the impact of the width of downward luminous intensity distribution, the calculation results were divided into four groups corresponding to the levels of the analyzed N1 indices. Table 6 presents the mean (Mean), minimum (Min), maximum (Max), range (R), and standard deviation of the mean (SD) values for the analyzed parameters.

Table 6. Variation of lighting parameters for each luminaire downward luminous intensity distribution (N1 index).

\begin{tabular}{lccccccc}
\hline Parameter & N1 & Cases & Mean & Min & Max & R & SD \\
\hline UN & & 108 & 0.678056 & 0.600000 & 0.780000 & 0.180000 & 0.043070 \\
EC/EN & & 108 & 0.772611 & 0.210000 & 1.652000 & 1.442000 & 0.420965 \\
EW/EN & 0.44 & 108 & 0.616537 & 0.538000 & 0.708000 & 0.170000 & 0.037484 \\
UT & & 108 & 0.802600 & 0.525762 & 1.069392 & 0.543629 & 0.136705 \\
PN100 & & 108 & 2.007221 & 1.461111 & 2.971875 & 1.510764 & 0.365538 \\
\hline UN & & 108 & 0.660741 & 0.550000 & 0.780000 & 0.230000 & 0.051495 \\
EC/EN & & 108 & 0.733796 & 0.192000 & 1.590000 & 1.398000 & 0.416133 \\
EW/EN & 0.58 & 108 & 0.519370 & 0.422000 & 0.656000 & 0.234000 & 0.054801 \\
UT & & 108 & 0.839034 & 0.545852 & 1.116071 & 0.570220 & 0.140600 \\
PN100 & & 108 & 1.918419 & 1.400000 & 2.862500 & 1.462500 & 0.345488 \\
\hline UN & & 108 & 0.657593 & 0.510000 & 0.790000 & 0.280000 & 0.065036 \\
EC/EN & & 108 & 0.712630 & 0.168000 & 1.548000 & 1.380000 & 0.412695 \\
EW/EN & 0.69 & 108 & 0.468426 & 0.346000 & 0.626000 & 0.280000 & 0.069816 \\
UT & & 108 & 0.859509 & 0.559284 & 1.140974 & 0.581690 & 0.142763 \\
PN100 & & 108 & 1.871904 & 1.369444 & 2.793750 & 1.424306 & 0.335077 \\
\hline UN & & 108 & 0.655833 & 0.470000 & 0.830000 & 0.360000 & 0.077942 \\
EC/EN & & 108 & 0.701333 & 0.154000 & 1.528000 & 1.374000 & 0.412061 \\
EW/EN & 0.77 & 108 & 0.436630 & 0.296000 & 0.606000 & 0.310000 & 0.079878 \\
UT & & 108 & 0.872085 & 0.568182 & 1.157407 & 0.589226 & 0.144810 \\
PN100 & & 108 & 1.844920 & 1.350000 & 2.750000 & 1.400000 & 0.330257 \\
\hline
\end{tabular}


The illuminance uniformity (UN) went up with the decrease in N1 level. However, this increase was low and amounted to $3.4 \%$ when comparing the edge solutions for $\mathrm{N} 1=0.77$ and $\mathrm{N} 1=0.44$. The EC/EN ceiling ratio also grew with the fall in N1 level. When comparing the solutions for $\mathrm{N} 1=0.77$ and $\mathrm{N} 1=0.69$, this increase was low, just $1.6 \%$, and when comparing the solutions for $\mathrm{N} 1=0.58$ and $\mathrm{N} 1=0.44$, the growth was $5.3 \%$. When comparing the edge solutions $(\mathrm{N} 1=0.77$ and $\mathrm{N} 1=0.44)$, the increase was $10 \%$. The EW/EN wall ratio also grew with the fall in N1 level. When comparing the solutions for $\mathrm{N} 1=0.77$ and $\mathrm{N} 1=0.69$, this increase was $7.3 \%$, and when comparing the solutions for $\mathrm{N} 1=0.58$ and $\mathrm{N} 1=0.44$, the growth was $19 \%$. When comparing the edge solutions $(\mathrm{N} 1=0.77$ and N1 $=0.44$ ), the increase amounted to $41 \%$. The room utilance (UT) grew up with the increase in $\mathrm{N} 1$ level. When comparing the edge solutions $(\mathrm{N} 1=0.44$ and $\mathrm{N} 1=0.77)$, this increase was $8.7 \%$. The normalized power density (PN100) fell down with the increase in N1 level. When comparing the edge solutions $(\mathrm{N} 1=0.44$ and $\mathrm{N} 1=0.77$ ), this decrease was $8.0 \%$. The changes in $\mathrm{N} 1$ level had the highest impact on the change in EW/EN.

\subsubsection{Impact of Luminaire Layout (SH)}

In order to determine the impact of luminaire layout, the calculation results were divided into three groups corresponding to the levels of the analyzed SH indices. Table 7 presents the mean (Mean), minimum (Min), maximum (Max), range (R), and standard deviations of the mean (SD) values for the analyzed parameters.

Table 7. Variation of lighting parameters for each luminaire layout (SH index).

\begin{tabular}{lccccccc}
\hline Parameter & SH & Cases & Mean & Min & Max & R & SD \\
\hline UN & & 144 & 0.652153 & 0.570000 & 0.730000 & 0.160000 & 0.036473 \\
EC/EN & & 144 & 0.739625 & 0.186000 & 1.594000 & 1.408000 & 0.411949 \\
EW/EN & 0.5 & 144 & 0.532722 & 0.354000 & 0.708000 & 0.354000 & 0.088248 \\
UT & & 144 & 0.836827 & 0.529661 & 1.138664 & 0.609003 & 0.143273 \\
PN100 & & 144 & 1.925772 & 1.372222 & 2.950000 & 1.577778 & 0.352231 \\
\hline UN & & 144 & 0.689444 & 0.600000 & 0.830000 & 0.230000 & 0.050960 \\
EC/EN & & 144 & 0.734125 & 0.172000 & 1.652000 & 1.480000 & 0.420697 \\
EW/EN & 1.0 & 144 & 0.515597 & 0.334000 & 0.688000 & 0.354000 & 0.090370 \\
UT & & 144 & 0.837765 & 0.525762 & 1.138952 & 0.613190 & 0.143474 \\
PN100 & & 144 & 1.924132 & 1.371875 & 2.971875 & 1.600000 & 0.355071 \\
\hline UN & & 144 & 0.647569 & 0.470000 & 0.790000 & 0.320000 & 0.079555 \\
EC/EN & & 144 & 0.716528 & 0.154000 & 1.638000 & 1.484000 & 0.414620 \\
EW/EN & 1.5 & 144 & 0.482403 & 0.296000 & 0.640000 & 0.344000 & 0.091959 \\
UT & & 144 & 0.855329 & 0.539827 & 1.157407 & 0.617580 & 0.143090 \\
PN100 & & 144 & 1.881944 & 1.350000 & 2.894444 & 1.544444 & 0.339141 \\
\hline
\end{tabular}

The illuminance uniformity (UN) gained the highest value for $\mathrm{SH}=1.0$. When comparing the solutions for $\mathrm{SH}=1.5$ and $\mathrm{SH}=1.0$, the increase in $\mathrm{UN}$ was $6.5 \%$, and when comparing the solutions for $\mathrm{SH}=1.0$ and $\mathrm{SH}=0.5$, the decrease in $\mathrm{UN}$ was $5.4 \%$. The changes in $\mathrm{UN}$ levels were negligible. The EC/EN ceiling ratio went up with the fall in SH level. When comparing the edge solutions $(\mathrm{SH}=1.5$ and $\mathrm{SH}=0.5)$, this increase was $3.2 \%$. The EW/EN wall ratio also grew with the fall in SH level. When comparing the edge solutions $(\mathrm{SH}=1.5$ and $\mathrm{SH}=0.5)$, this increase was $10 \%$. The utilance (UT) went up with the growth in $\mathrm{SH}$ level. When comparing the edge solutions $(\mathrm{SH}=1.5$ and $\mathrm{SH}=0.5)$, this increase was only $2.2 \%$. The normalized power density (PN100) fell down with the increase in $\mathrm{SH}$ level. When comparing the edge solutions ( $\mathrm{SH}=1.5$ and $\mathrm{SH}=0.5)$, this decrease was only $2.2 \%$. The changes in SH level had a low impact on the changes in average values of the analyzed photometric parameters. 


\subsubsection{Summary 1}

The results summarizing the analysis of the impact of individual parameters characterizing rooms, luminaires, and their layout on the average values of the analyzed parameters are presented in Table 8 .

Table 8. Average changes of UN, EC/EN, EW/EN, UT, PN100 due to changes of RI, RE, N4, N1, SH.

\begin{tabular}{cccccc}
\hline Parameter & \%UN & \%EC/EN & \%EW/EN & \%UT & \%PN100 \\
\hline RI & $\uparrow+14 \%$ & $\downarrow+24 \%$ & $<10 \%$ & $\uparrow+\mathbf{2 6 \%}$ & $\uparrow-\mathbf{2 1 \%}$ \\
RE & $<10 \%$ & $<10 \%$ & $<10 \%$ & $<10 \%$ & $<10 \%$ \\
N4 & $<10 \%$ & $\downarrow+455 \%$ & $\downarrow+24 \%$ & $\uparrow+42 \%$ & $\uparrow-30 \%$ \\
N1 & $<10 \%$ & $\downarrow+10 \%$ & $\downarrow+41 \%$ & $<10 \%$ & $<10 \%$ \\
SH & $<10 \%$ & $<10 \%$ & $\downarrow+10 \%$ & $<10 \%$ & $<10 \%$
\end{tabular}

$\uparrow(\downarrow)$ indicates increase (decrease) of RI, N4, N1, SH; +(-) indicates increase (decrease) of UN $, E C / E N, E W / E N$, UT, PN100.

The most significant changes in the average values of the analyzed parameters are marked in red. These changes were obtained while comparing the edge values of RI, RE, N4, N1, and SH. At the next stage, these cases were analyzed in detail.

\subsection{Impact of $N 4$ and RI on Changes in EC/EN}

The N4 index was the parameter having the highest impact on the level of the ceiling ratio EC/EN. Regardless of the room size, reducing the $\mathrm{N} 4$ level led to a very significant growth in EC/EN level (Figure 6a). A lower impact of the changes in N4 index on the EC/EN ceiling ratio level could be observed in the rooms with a higher RI index. When comparing the edge solutions ( $\mathrm{N} 4=1.00$ and $\mathrm{N} 4=0.25$ ) in the room with $\mathrm{RI}=1.5$, reducing the $\mathrm{N} 4$ level caused an increase in EC/EN ceiling ratio of $523 \%$. However, when comparing the edge solutions in the room with $\mathrm{RI}=4.5$, the EC/EN ceiling ratio grew by $407 \%$.

The RI index was also a parameter having a quite significant impact on the EC/EN ceiling ratio level. As a result of the changes in RI index, the changes in EC/EN ceiling ratio level were of a similar nature for the various $\mathrm{N} 4$ indices (Figure $6 \mathrm{~b}$ ). When comparing the edge solutions ( $\mathrm{RI}=4.5$ and $\mathrm{RI}=1.5$ ) for $\mathrm{N} 4=1.00$, lowering the RI level caused an increase in EC/EN ceiling ratio of only $6.3 \%$. On the other hand, when comparing the edge solutions for $\mathrm{N} 4=0.25$, the EC/EN ceiling ratio grew by $31 \%$.

\subsection{Impact of $N 4$ and $N 1$ on Changes in EW/EN}

The N4 index was a parameter having the highest impact on the EW/EN wall ratio level. However, this impact had a different nature depending on the N1 index level (Figure 7a). A lower impact of N4 index on the EW/EN wall ratio level could be observed for the luminaires with a lower N1 index. When comparing the solutions for the luminaires with $\mathrm{N} 1=0.44$, the changes in EW/EN wall ratio level for the various $\mathrm{N} 4$ indexes did not exceed $10 \%$. When comparing the edge solutions (N4 = 1.00 and $\mathrm{N} 4=0.25$ ) for the luminaires with $\mathrm{N} 1=0.58$, reducing the $\mathrm{N} 4$ index level already caused an increase in EW/EN wall ratio of $21 \%$. Nevertheless, when comparing the edge solutions for the luminaires with $\mathrm{N} 1=0.77$, lowering the N4 index level caused a growth in the EW/EN wall ratio of up to $52 \%$. 


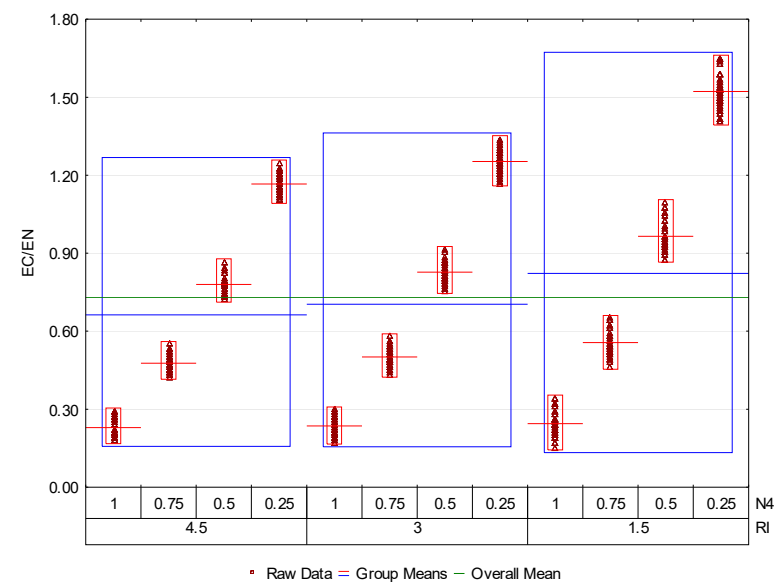

(a)

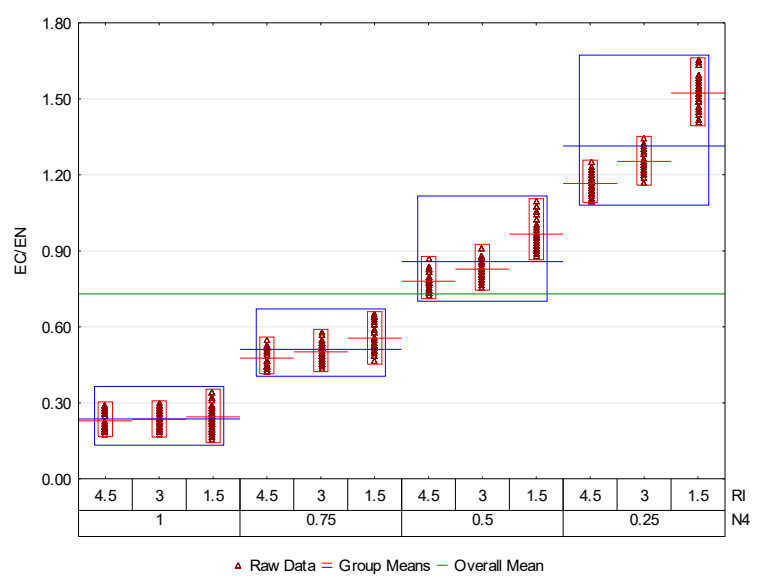

(b)

Figure 6. Variability plots of EC/EN illustrating: (a) N4 impact for various RI; (b) RI impact for various $\mathrm{N} 4$.

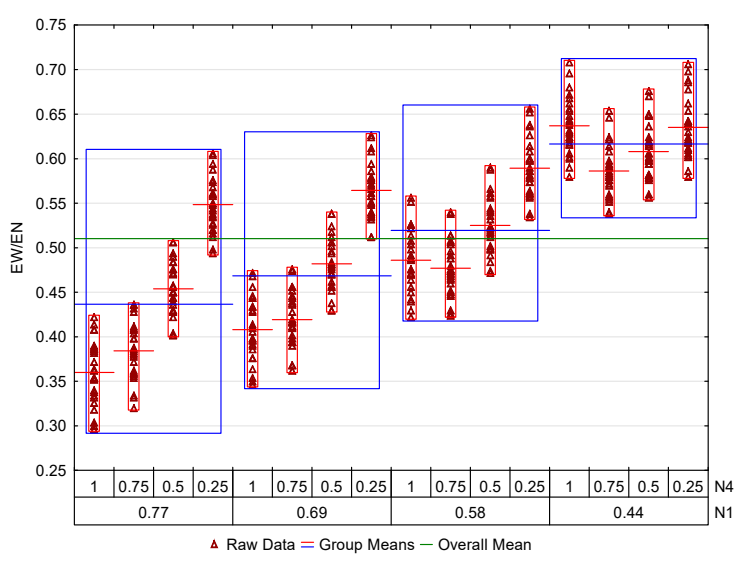

(a)

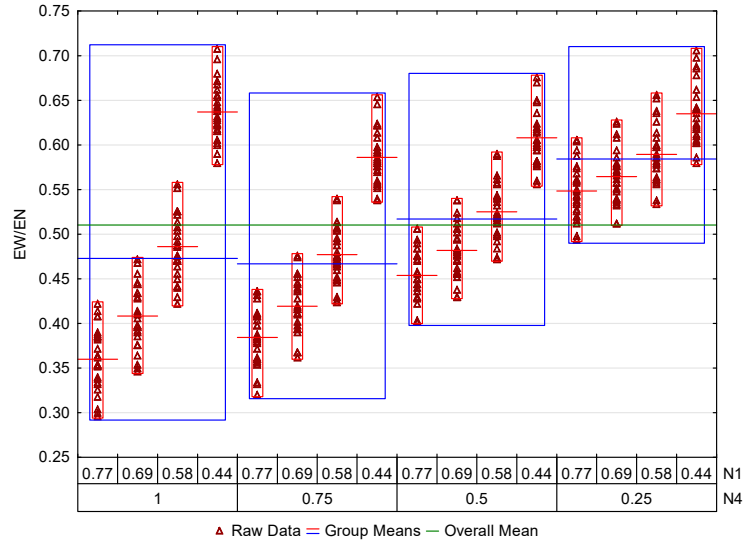

(b)

Figure 7. Variability plots of EW/EN illustrating: (a) N4 impact for various N1; (b) N1 impact for various N4. 
The N1 index was also a parameter having an impact on the EW/EN wall ratio level. Regardless of the value of N4 index, the change in N1 index level of the luminaires led to increasing the EW/EN wall ratio (Figure $7 \mathrm{~b}$ ). The increase in EW/EN wall ratio level was, however, much higher as for the luminaires with a higher N4 index. When comparing the edge solutions $(\mathrm{N} 1=0.77$ and $\mathrm{N} 1=0.44)$ for the luminaires with $\mathrm{N} 4=0.25$, reducing the $\mathrm{N} 1$ index level caused a growth in the EW/EN wall ratio of $16 \%$. On the other hand, when comparing the edge solutions for the luminaires with $\mathrm{N} 4=1.00$, lowering the $\mathrm{N} 1$ index level caused a growth in the EW/EN wall ratio of up to $77 \%$.

\subsection{Impact of $N 4$ and RI on Changes in UT}

The N4 index was the parameter having the highest impact on the UT level. Regardless of the room size, the increase in N4 index level led to a significant increase in the UT level (Figure 8a). A lower impact of N4 index on the UT level occurred in the rooms with a higher RI index. When comparing the edge solutions ( $\mathrm{N} 4=1.00$ and $\mathrm{N} 4=0.25)$ in the room with $\mathrm{RI}=4.5$, increasing the $\mathrm{N} 4$ index level caused a growth in UT level of 39\%. However, when comparing the edge solutions in the room with $\mathrm{RI}=1.5$, the increase in UT level was $50 \%$.

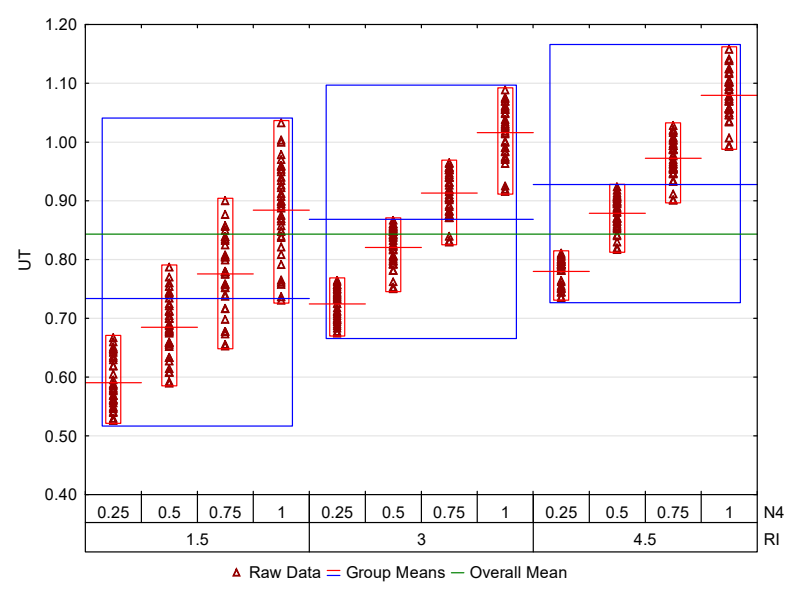

(a)

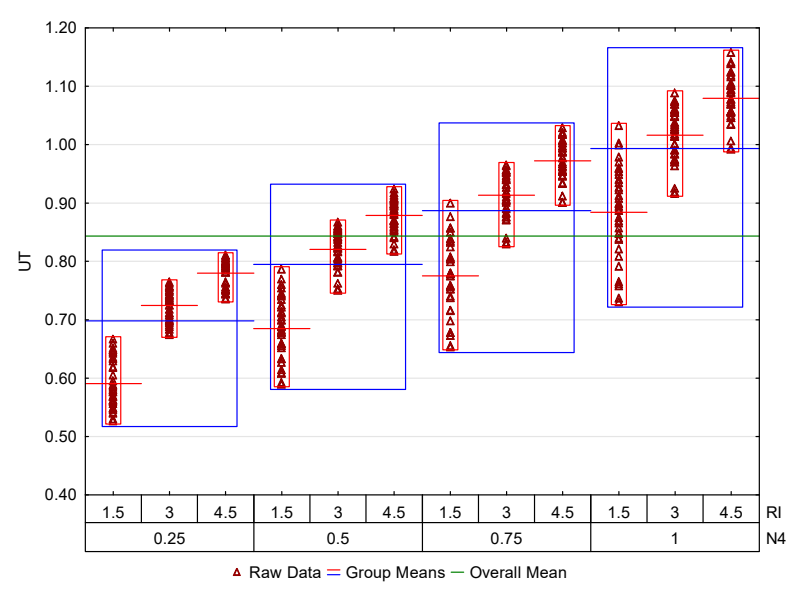

(b)

Figure 8. Variability plots of UT illustrating: (a) N4 impact for various RI; (b) RI impact for various N4.

The RI index was also a parameter having a significant impact on the UT level. Regardless of the value of N4 index, the increase in RI level led to an increase in the UT index (Figure 8b). A lower impact of RI index on the UT index level occurred in the rooms with a higher N4 index. When comparing the 
edge solutions ( $R I=4.5$ and $R I=1.5$ ) for $N 4=1.00$, increasing the $R I$ index level caused an increase in UT level of $22 \%$. However, when comparing the edge/outermost solutions for N4 $=0.25$, the UT index grew by $32 \%$.

\subsection{Impact of N4 and RI on Changes in PN100}

The N4 index was the parameter having the highest impact on the PN100 level. Regardless of the room size, the increase in N4 level led to a significant decrease in PN100 level (Figure 9a). A lower impact of N4 index on the PN100 level occurred in the rooms with a higher RI index. When comparing the edge solutions ( $\mathrm{N} 4=1.00$ and $\mathrm{N} 4=0.25)$ in the room with $\mathrm{RI}=4.5$, increasing the $\mathrm{N} 4$ index level caused a fall in PN100 level of $28 \%$. On the other hand, when comparing the edge solutions in the room with $\mathrm{RI}=1.5$, the PN level fell down by $33 \%$.

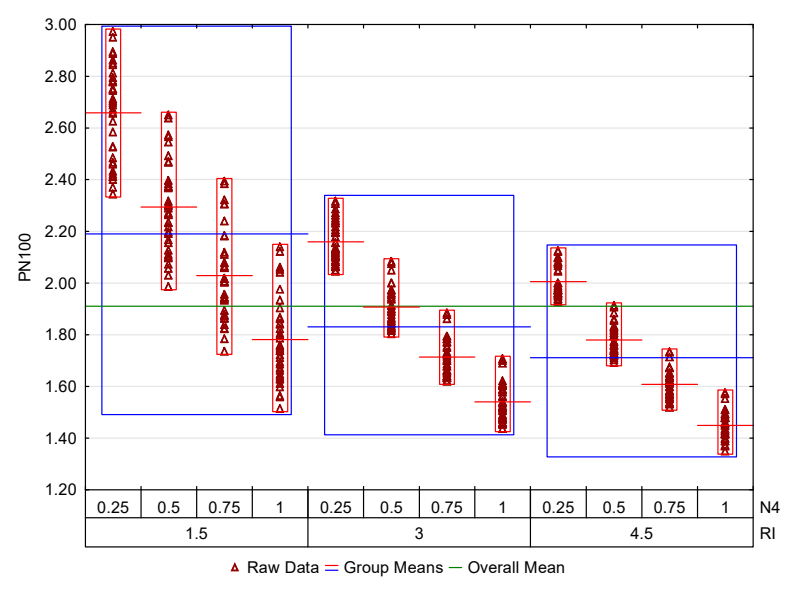

(a)

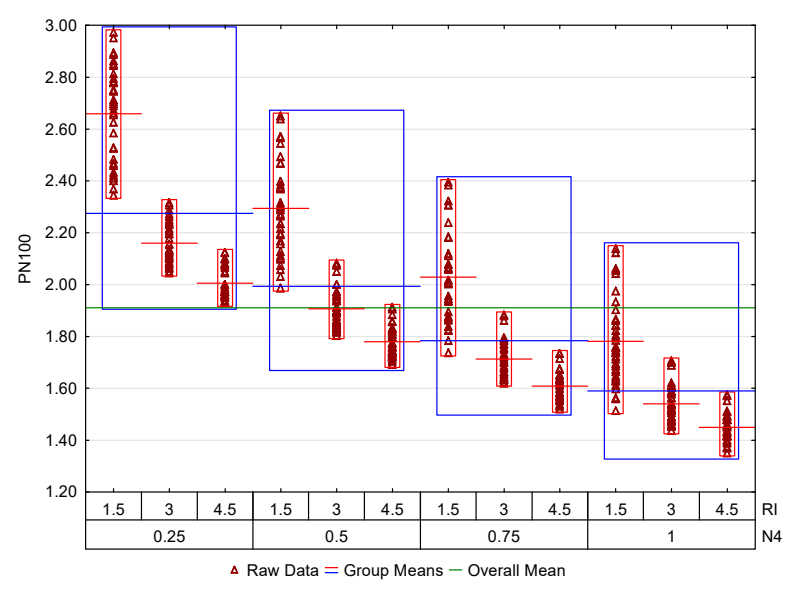

(b)

Figure 9. Variability plots of PN100 illustrating: (a) N4 impact for various RI; (b) RI impact for various $\mathrm{N} 4$.

The RI index was also a parameter having a significant impact on the PN100 level. Regardless of the value of N4 index, the increase in RI level led to a fall in PN100 level (Figure 9b). A lower impact of $\mathrm{RI}$ index on the PN100 level occurred in the rooms with a higher N4 index. When comparing the edge solutions (RI $=4.5$ and $\mathrm{RI}=1.5)$ for $\mathrm{N} 4=1.00$, increasing the RI index level caused a decrease in PN100 of $18 \%$. On the other hand, when comparing the edge solutions for $\mathrm{N} 4=0.25$, the PN level fell down by $24 \%$. 


\subsection{Summary 2}

The impact of lighting class (N4 index) on the EC/EN ceiling ratio level was very high, but it was higher in the smaller rooms. The lighting class (N4 index) had a significantly higher impact on the $\mathrm{EW} / \mathrm{EN}$ wall ratio level when using the luminaires with narrower luminaire downward luminous intensity distributions. The luminaire downward luminous intensity distribution (N1 index) had a significantly higher impact on the EW/EN wall ratio level for direct lighting than for higher lighting classes. In the larger rooms, the impact of lighting class (N4 index) on the level of the increase in utilance (UT) and the decrease in normalized power density (PN100) was lower than in the smaller rooms.

The scope of conducted research is much broader than the investigations conducted so far in $[30,31,38]$. This mainly applies to the room size, types of luminaires and their layouts. The results obtained show a significant impact of lighting class on ceiling and wall illumination, lighting installation utilance, and normalized power density. The results also demonstrate that in larger rooms, the impact of lighting class on the ceiling illumination level, lighting installation utilance, and normalized power density is lower than in smaller rooms. Therefore, the obtained results verify the thesis presented in [31].

\subsection{Power of General Lighting in Interiors}

At the final stage of the research, the normalized power density levels (PN) were determined for different levels of the luminous efficacies and light output ratios of luminaires, and the maintenance factors. The calculations were carried out for the range of the obtained levels of lighting installation utilance (UT) (Table 2). Figure 10 shows the normalized power densities for the following parameter levels:

- $\quad$ LE: 50 lm/W (low), 100 lm/W (moderate), 150 lm/W (high), 200 lm/W (very high);

- LOR: 0.8 (relatively high) and 0.6 (relatively low);

- MF: 0.8 (relatively high) and 0.7 (relatively low).

It can be observed that the normalized power density for the low luminous efficacy ranges from approx. $3 \mathrm{~W} / \mathrm{m}^{2}$ per $100 \mathrm{~lx}$ to approx. $9 \mathrm{~W} / \mathrm{m}^{2}$ per $100 \mathrm{~lx}$. The use of light sources with a luminous efficacy LE $=100 \mathrm{~lm} / \mathrm{W}$ and more allows us to obtain the normalized power density below $2 \mathrm{~W} / \mathrm{m}^{2}$ per 100 lx. For very high LE levels, but also for LE $=150 \mathrm{~lm} / \mathrm{W}$ and very high UT levels, it is possible to gain the normalized power density lower than $1 \mathrm{~W} / \mathrm{m}^{2}$ per $100 \mathrm{~lx}$.

On the basis of the obtained results representing a very wide range of the lighting solutions, a classification on the energy efficiency of interior lighting based on the normalized power density was proposed, shown in Table 9.

Looking at the results presented in Figure 10, it is worth noting that a high LE value (at least $100 \mathrm{~lm} / \mathrm{W}$ ) gives a high potential for achieving the high energy efficiency in interior lighting. At the same time, the possibility of gaining the low values of normalized power density (lower than $4 \mathrm{~W} / \mathrm{m}^{2}$ per 100 lx) should be recognized even when using the light sources with a luminous efficacy of $50 \mathrm{~lm} / \mathrm{W}$. However, it requires obtaining a high efficiency of the lighting installation utilance (UT) while using the luminaires of a high LOR value. 


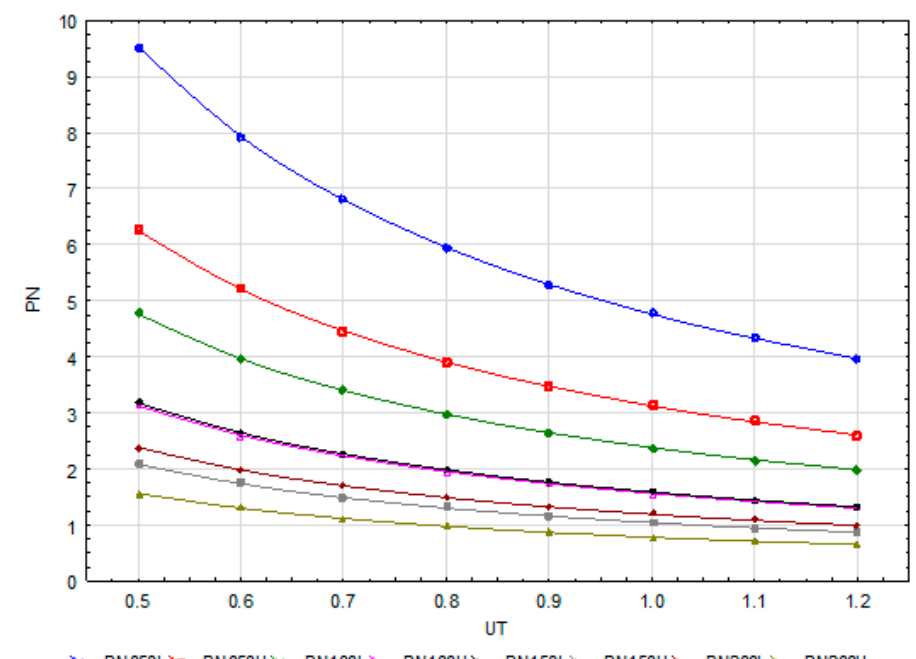

PN050L indicates normalized power density for $\mathrm{LE}=50 \mathrm{~lm} / \mathrm{W}, \mathrm{LOR}=0.6$ and $\mathrm{MF}=0.7$

$\mathrm{PN} 050 \mathrm{H}$ indicates normalized power density for $\mathrm{LE}=50 \mathrm{~lm} / \mathrm{W}, \mathrm{LOR}=0.8$ and $\mathrm{MF}=0.8$

$\mathrm{PN} 100 \mathrm{~L}$ indicates normalized power density for $\mathrm{LE}=100 \mathrm{~lm} / \mathrm{W}, \mathrm{LOR}=0.6$ and $\mathrm{MF}=0.7$

$\mathrm{PN} 100 \mathrm{H}$ indicates normalized power density for $\mathrm{LE}=100 \mathrm{~lm} / \mathrm{W}, \mathrm{LOR}=0.8$ and $\mathrm{MF}=0.8$

$\mathrm{PN} 150 \mathrm{~L}$ indicates normalized power density for $\mathrm{LE}=150 \mathrm{~lm} / \mathrm{W}, \mathrm{LOR}=0.6$ and $\mathrm{MF}=0.7$

$\mathrm{PN} 150 \mathrm{H}$ indicates normalized power density for $\mathrm{LE}=150 \mathrm{~lm} / \mathrm{W}, \mathrm{LOR}=0.8$ and $\mathrm{MF}=0.8$

$\mathrm{PN} 200 \mathrm{~L}$ indicates normalized power density for $\mathrm{LE}=200 \mathrm{~lm} / \mathrm{W}, \mathrm{LOR}=0.6$ and $\mathrm{MF}=0.7$

$\mathrm{PN} 200 \mathrm{H}$ indicates normalized power density for $\mathrm{LE}=200 \mathrm{~lm} / \mathrm{W}, \mathrm{LOR}=0.8$ and $\mathrm{MF}=0.8$

Figure 10. The normalized power density $\mathrm{PN}\left[\mathrm{W} / \mathrm{m}^{2}\right.$ per $\left.100 \mathrm{~lx}\right]$ in interiors for various LE, LOR, and MF levels.

Table 9. The energy efficiency classification proposal for interior lighting based on the normalized power density $\mathrm{PN}\left[\mathrm{W} / \mathrm{m}^{2}\right.$ per $\left.100 \mathrm{~lx}\right]$.

\begin{tabular}{lc}
\hline \multicolumn{1}{c}{ Lighting Energy Efficiency Class } & PN \\
\hline A: The most energy efficient & $\leq 1.0$ \\
B: Very energy efficient & $>1.0-2.0$ \\
C: Energy efficient & $>2.0-3.0$ \\
D: Intermediate energy efficient & $>3.0-4.0$ \\
E: Low energy efficient & $>4.0-5.0$ \\
F: Very low energy efficient & $>5.0-6.0$ \\
G: The least energy efficient & $>6.0$ \\
\hline
\end{tabular}

\section{Conclusions}

For a wide range of the parameters characterizing rooms, luminaires, and their layout, it is possible to obtain:

- uniformity levels on work plane that are high (UN $>0.6$ for almost $90 \%$ of all solutions) and very high (UN > 0.7 for almost $25 \%$ of all solutions);

- $\quad$ a very wide range of ceiling relative illuminaces (EC/EN from 0.15 to 1.65 );

- a quite limited range of wall relative illuminaces (EW/EN from 0.30 to 0.71 );

- lighting installation utilance levels that are high (UT $>0.7$ for almost $85 \%$ of all solutions) and very high (UT $>0.9$ for over $35 \%$ of all solutions). 
The lighting class and room size are the key factors determining the levels of ceiling relative illuminance, lighting installation utilance, and normalized power density. The lighting class and the luminaire downward luminous intensity distribution are the key factors determining the level of the wall relative illuminance. The impact of floor and wall reflectances and the luminaire layout, for the ranges of these variables considered in this paper, on all the analyzed parameters is low.

The obtained results and formulated conclusions refer to a wide range of cases, however, they are limited by the adopted assumptions. In order to generalize the results fuller, it is necessary to verify whether the obtained results are also applicable in rooms with other characteristics and for other types and layouts of luminaires. In particular, it is necessary to check the impact of room proportions, other luminaire luminous intensity distributions and layouts, as well as other ceiling, wall, and floor reflectances on lighting parameters in interiors.

The level of normalized power density in interior lighting, apart from the lighting installation utilance, also depends on the luminous efficacy of light sources, the light output ratio of luminaire, and the maintenance factor. The use of general lighting and light sources with a high luminous efficacy (at the level of $150 \mathrm{~lm} / \mathrm{W}$ ) should provide the normalized power density in interior lighting not exceeding a level of $3 \mathrm{~W} / \mathrm{m}^{2}$ per $100 \mathrm{~lx}$.

Author Contributions: Conceptualization, P.P.; methodology, P.P.; software, P.P., M.D., P.K.; validation, P.P., M.D., P.K.; formal analysis, P.P.; resources, P.P.; data curation, P.P.; writing-original draft preparation, P.P.; writing-review and editing, P.P., M.D., P.K.; visualization, P.P.; supervision. All authors have read and agreed to the published version of the manuscript.

Funding: This research received no external funding.

Acknowledgments: Article Preparation Charge was covered by the Electrical Power Engineering Institute at the Warsaw University of Technology and Open Access Charge was covered by IDUB program at the Warsaw University of Technology.

Conflicts of Interest: The authors declare no conflict of interest.

\section{References}

1. Apanaviciene, R.; Vanagas, A.; Fokaides, P.A. Smart building integration into a smart city (SBISC): Development of a new evaluation framework. Energies 2020, 13, 2190. [CrossRef]

2. Veitch, J.A. Light, lighting, and health: Issues for consideration. Leukos 2005, 2, 85-96. [CrossRef]

3. Dikel, E.E.; Veitch, J.A.; Mancini, S.; Xue, H.H.; Valdés, J.J. Lighting-on-Demand: Balancing occupant needs and energy savings. Leukos 2018, 14,3-11. [CrossRef]

4. Montoya, F.G.; Peña-García, A.; Juaidi, A.; Manzano-Agugliaro, F. Indoor lighting techniques: An overview of evolution and new trends for energy saving. Energy Build. 2017, 140, 50-60. [CrossRef]

5. Leśko, M.; Różowicz, A.; Wachta, H.; Różowicz, S. Adaptive luminaire with variable luminous intensity distribution. Energies 2020, 13, 721. [CrossRef]

6. Leoto, R.; Lizarralde, G. Challenges in evaluating strategies for reducing a building's environmental impact through integrated design. Build. Environ. 2019, 155, 34-46. [CrossRef]

7. Pracki, P.; Skarżyński, K. A multi-criteria assessment procedure for outdoor lighting at the design stage. Sustainability 2020, 12, 1330. [CrossRef]

8. Dillon, H.E.; Ross, C.; Dzombak, R. Environmental and energy improvements of LED lamps over time: A comparative life cycle assessment. Leukos 2020, 16, 229-237. [CrossRef]

9. Beccali, M.; Bonomolo, M.; Leccese, F.; Lista, D.; Salvadori, G. On the impact of safety requirements, energy prices and investment costs in street lighting refurbishment design. Energy 2018, 16, 739-759. [CrossRef]

10. Rea, M.S. Lighting simply made better: Providing a full range of benefits without much fuss. Build. Environ. 2018, 144, 57-65. [CrossRef]

11. Chraibi, S.; Crommentuijn, L.; van Loenen, E.; Rosemann, A. Influence of wall luminance and uniformity on preferred task illuminance. Build. Environ. 2017, 117, 24-35. [CrossRef]

12. Rea, M.S.; Ouellette, M.J. Relative visual performance: A basis for application. Light. Res. Technol. 1991, 23, 135-144. [CrossRef] 
13. Scheir, G.H.; Hanselaer, P.; Ryckaert, W.R. Pupillary light reflex, receptive field mechanism and correction for retinal position for the assessment of visual discomfort. Light. Res. Technol. 2019, 51, 291-303. [CrossRef]

14. Berson, D.M. Strange vision: Ganglion cells as circadian photoreceptors. Trends Neurosci. 2003, 26, $283-334$. [CrossRef]

15. Figueiro, M.G. Disruption of circadian rhythms by light during day and night. Curr. Sleep Med. Rep. 2017, 3, 76-84. [CrossRef]

16. Moscoso, C.; Chamilothori, K.; Wienold, J.; Andersen, M.; Matusiak, B. Window size effects on subjective impressions of daylit spaces: Indoor studies at high latitudes using virtual reality. Leukos 2020. [CrossRef]

17. Bellia, L.; Fragliasso, F.; Stefanizzi, E. Effects of light source spectrum and background colour on the perception of paintings. Light. Res. Technol. 2020, 52, 36-63. [CrossRef]

18. Flynn, J.E.; Hendrick, C.; Spencer, T.; Martyniuk, O. A guide to methodology procedures for measuring subjective impressions in lighting. J. Illum. Eng. Soc. 1979, 8, 95-110. [CrossRef]

19. Ferlazzo, F.; Piccardi, L.; Burattini, C.; Barbalace, M.; Giannini, A.M.; Bisegna, F. Effects of new light sources on task switching and mental rotation performance. J. Environ. Psychol. 2015, 39, 92-100. [CrossRef]

20. Veitch, J.A.; Stokkermans, M.G.M.; Newsham, G.R. Linking lighting appraisals to work behaviors. Environ. Behav. 2013, 45, 198-214. [CrossRef]

21. Krupiński, R. Dynamically variable luminance distribution as the method of designing and architectural floodlighting. In Proceedings of the 2016 IEEE Lighting Conference of the Visegrad Countries (Lumen V4), Karpacz, Poland, 13-16 September 2016; pp. 1-4.

22. Boyce, P.R.; Veitch, J.A.; Newsham, G.R.; Jones, C.C.; Heerwagen, J.; Myer, M.; Hunter, C.M. Lighting quality and office work: Two field simulation experiments. Light. Res. Technol. 2006, 38, 191-223. [CrossRef]

23. Castilla, N.; Llinares, C.; Bisegna, F.; Blanca-Giménez, B. Emotional evaluation of lighting in university classrooms: A preliminary study. Front. Arch. Res. 2018, 7, 600-609. [CrossRef]

24. Pracki, P. Impact of direct lighting Luminaires' luminous intensity distribution on lighting quality in interiors. In Proceedings of the 2018 VII Lighting Conference of the Visegrad Countries (Lumen V4), Trebic, Czech Republic, 18-20 September 2018; pp. 1-6.

25. Benavente-Peces, C. On the energy efficiency in the next generation of smart buildings-Supporting technologies and techniques. Energies 2019, 12, 4399. [CrossRef]

26. European Standard EN 12464-1:2011. Light and Lighting_Lighting of Work Places_Part 1: Interior Work Places; CEN: Brussels, Belgium, 2011.

27. European Standard EN 15193-1:2017. Energy Performance of Buildings—Energy Requirements for Lighting-Part 1: Specifications, Module M9; CEN: Brussels, Belgium, 2017.

28. Lo Verso, V.R.M.; Pellegrino, A.; Pellerey, F. A multivariate non-linear regression model to predict the energy demand for lighting in rooms with different architectural features and lighting control systems. Energy Build. 2014, 76, 151-163. [CrossRef]

29. Yoomak, S.; Ngaopitakkul, A. Optimisation of lighting quality and energy efficiency of LED luminaires in roadway lighting systems on different road surfaces. Sustain. Cities Soc. 2018, 38, 333-347. [CrossRef]

30. Makaremi, N.; Schiavoni, S.; Pisello, A.L.; Asdrubali, F.; Cotana, F. Quantifying the effects of interior surface reflectance on indoor lighting. Energy Procedia 2017, 134, 306-316. [CrossRef]

31. Makaremi, N.; Schiavoni, S.; Pisello, A.L.; Cotana, F. Effects of surface reflectance and lighting design strategies on energy consumption and visual comfort. Indoor Built Environ. 2019, 28, 552-563. [CrossRef]

32. Mangkuto, R.A. Validation of DIALux 4.12 and DIALux evo 4.1 against the Analytical Test Cases of CIE 171:2006. Leukos 2016, 12, 139-150. [CrossRef]

33. Mattoni, B.; Gori, P.; Bisegna, F. A step towards the optimization of the indoor luminous environment by genetic algorithms. Indoor Built Environ. 2015, 26, 590-607. [CrossRef]

34. Lowry, G. Energy saving claims for lighting controls in commercial buildings. Energy Build. 2016, 133, $489-497$. [CrossRef]

35. Nisbet, R.; Elder, J.; Miner, G. Handbook of Statistical Analysis and Data Mining Applications; Elsevier: Oxford, UK, 2009.

36. CIE Website. Available online: http://eilv.cie.co.at/term/463 (accessed on 26 August 2020). 
37. CIE Website. Available online: http://eilv.cie.co.at/term/1121 (accessed on 26 August 2020).

38. Pracki, P. The impact of room and luminaire characteristics on general lighting in interiors. Bull. Pol. Acad. Sci. Tech. Sci. 2020, 68, 447-457.

(). (1) (C) 2020 by the authors. Licensee MDPI, Basel, Switzerland. This article is an open access article distributed under the terms and conditions of the Creative Commons Attribution (CC BY) license (http://creativecommons.org/licenses/by/4.0/). 